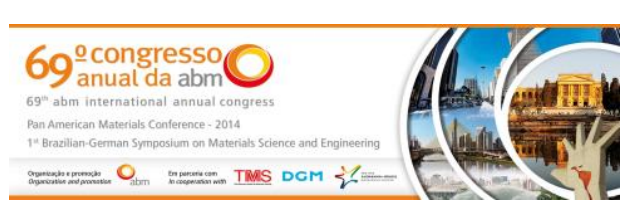

Tema: Nanotecnologia

\title{
EFFECTS OF THE INCORPORATION OF CLAY ON PROPERTIES OF THE BIODEGRADABLE COPOLYESTER/PLA FLEXIBLE FILM*
}

\begin{abstract}
Nowadays, population growth and the interest of food industry, makes the research and applications of biodegradable polymers increase, because under favorable conditions its degradations may occur within weeks or in a few months, reducing the environmental impact. This work presents the processing and characterization of flexible films by the incorporation of 3 $\%(\% \mathrm{wt})$ of modified bentonite light green clay in the Copolyester/PLA biodegradable blend. The clay incorporation was carried out by melt-mixing processing, using a twin screw extruder machine. The films were obtained by cast extrusion tape. The films obtained were submitted to tensile tests, SEM and XRD analysis, and the correlation between their properties was discussed. The XRD results of clay showed that the quaternary salt and sodium carbonate addition increased the interlayer distance of clay making it easier to intercalation of blend in the nanoclay. The XRD results of PBAT/PLA/Clay nanocomposite show no characteristic organoclay peaks. This result suggests intercalation between nanoclay and matrix (blend). The tensile test results showed an increase of around $30 \%$ in tensile strength at break of nanocomposite film when compared with blend film.
\end{abstract}

Keywords: Biodegradable polymer; Clay; Flexible films; Mechanical properties.

1 Graduação em Química Industrial, estudante de mestrado, Centro de Química e Meio Ambiente (CQMA), Instituto de Pesquisas Energéticas e Nucleares (IPEN), São Paulo, SP, Brasil.

2 Graduação, Tecnologia em Polímeros, estudante, estagiário de iniciação cientifica, CQMA, IPEN, São Paulo, SP, Brasil.

3 Chemistry M.Sc., Ph.D. student, Center for Advanced Materials, Tuskegee University, Alabama, USA.

4 Chemistry, Ph.D., Research Associate Prof., Center for Advanced Materials, Tuskegee University, Alabama, USA.

5 Mechanical Engineering, Ph.D., Director, Center for Advanced Materials, Tuskegee University, Alabama, USA.

6 Graduação, Eng. Química, Ph.D., Professor, Faculdade de Eng. Met. e Mat., USP, São Paulo, SP, Brasil.

7 Graduação, Eng, Química, Ph. D., Pesquisador e Orientador do Programa de Pós-Gaduação, CQMA, IPEN, USP, São Paulo, SP, Brasil. 


\section{INTRODUCTION}

Due to environment and sustainability issues, this century has witnessed remarkable achievements in green technology in the field of materials science through the development of biocomposites. The development of high-performance materials made from natural resources is increasing worldwide. With the developments of biodegradable materials, other researchers are trying to use directly the biomass constituents to manufacture polymeric materials $[1,2]$.

Increasing population, scarcity of raw materials coupled with global warming issues has governments and corporations looking for opportunities such as recycling and biodegradability to expand material performance [3].

Since plastic packaging materials are often contaminated by food materials and biological substances, recycling of these materials is often impractical and most of the time not economical [4].

Biopolymers should be used in those applications where biodegradability and/or the derivation of natural resources gives added value, particularly, where valuable petroleum-based plastics are used for applications with a short life time [5].

The term "biodegradable" materials is used to describe those materials which can be degraded by the enzymatic action of living organisms, such as bacteria, yeasts, fungi and the ultimate end-products of the degradation process, these being $\mathrm{CO}_{2}, \mathrm{H}_{2} \mathrm{O}$, and biomass under aerobic conditions and hydrocarbons, methane and biomass under anaerobic conditions [6].

The recent incorporation of biological waste treatment (i.e., composting and biogasification) in an integrated approach to solid waste management has resulted in a growing commercial interest in the development of biodegradable materials for consumer products $[4,5]$. On the market are a number of materials known as biodegradable plastics (i.e., starch-based materials, cellulose-derived polymers, bacterial polyesters and a range of synthetic polymers) [7]. Among commercial biodegradable plastics, aliphatic-aromatic copolyester (PBAT) is one of the most promising biodegradable materials because they are readily susceptible to biological attack [8]. PBAT has gained research and industry attention due to good processability in extrusion lines LDPE; besides PBAT begins to degrade after only few days in soil and enzymatic environments in contrast to petroleum derived polymers, such as polypropylene, polyethylene, that takes hundreds or even thousands of years to degrade $[8,9]$.

The PBAT (butylene adipate-co-terepthalate) and the PLA (Poly(lactic acid)), have been extensively investigated as biodegradable polyesters and have a large number of biomedical applications such as absorbable bone plates, some surgical fixation devices, bioabsorbable surgical sutures and carriers for the controlled release of drugs. These aliphatic polyesters are commercially produced either by microorganisms, ring-opening polymerization of lactones or ring-opening poly addition of cyclic dimmers [10-12].

The combination of these two materials in a blend (PBAT/PLA), aims to bring the best characteristics for a biodegradable material, therefore aliphatic polyesters are the most promising biodegradable materials because they are readily susceptible to biological attack $[13,14]$.

Polymer blending is a well-used technique whenever modification of properties is required, because it uses conventional technology at low cost. The usual objective for preparing a novel blend of two or more polymers is not to change the properties of

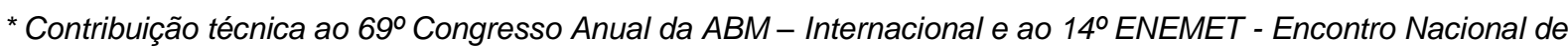
Estudantes de Engenharia Metalúrgica, de Materiais e de Minas, 21 a 25 de julho de 2014, São Paulo, SP, Brasil. 
the components drastically, but to capitalize on the maximum possible performance of the blend [15]

The modification of polymers, through the incorporation of additives in the micrometer range, can either improve modify the modulus and the strength (carbon black, silica beads and fibers, clay, mica) [16]. Recently the application of the nanocomposite concept has proven to be a promising option in order to improve mechanical and barrier properties [5].

Polymer nanocomposites are two-phase materials, in which the polymers are reinforced by nanoscale fillers [16]. Organoclay-based nanocomposites can be a potential candidate because of their mechanical, thermal, gas barrier, and optical properties at low clay content [17].

Since the creation of flexible films, the packaging industry has been propelled to astonishing heights. Through the development and utilization of these films, manufacturing practices, and continual innovations, the field of packaging has been able to grow and evolve to adapt to the needs of products around the globe.

The aim of this work is to produce biodegradable flexible film through a polymeric nanocomposite consisting of biodegradable copolyester, PLA and nanoclay, for the film to be used with dry foods.

\subsection{Biodegradable Copolyester (PBAT)}

The Poly (butylene adipate-co-terepthalate) (PBAT), an aliphatic-aromatic copolyester based on terephthalic acid, adipic acid, 1,4- butanediol and modular units is used in industrial applications [9]. This product was basically designed to meet the requirements of a biodegradable plastic; a combination of melt processability, end use performance and biodegradability. The films are tear-resistant and flexible, and also resistant to both water and fluctuations in humidity. The PBAT can be processed by conventional blown film lines for PELD. [4,9].

Typical applications of PBAT are compost bags for organic waste, films in the agricultural sector, household films, and coating or lamination (e.g., paper), and coating materials for starch-based products (e.g., plates, cups) within the fast food and catering industries [9].

The PBAT is considered a good candidate for the toughening of PLA due to its high toughness and biodegradability and no indication of environmental risk (ecotoxicity) when are introduced into composting processes [18,19].

\subsection{PLA}

Poly(lactic acid) (PLA) is a linear, semicrystalline, aliphatic, biodegradable polyester that can be produced from lactic acid by the fermentation of renewable sources such as whey ,corn, potato, or molasses [20]. Polymerization of lactic acid into PLA produces a biodegradable thermoplastic polyester with good biocompatibility and physical properties, such as high mechanical strength, thermoplasticity, fabricability, and shows a number of interesting properties including biodegradability, high strength and high modulus [21].

The PLA is considered synthetic biodegradable polymer class, and this group of polymers has been widely used in biomedical uses, such as controlled-release capsules of drugs in living organisms, fasteners surgery (sutures, implants for bone pins) and special candidate for producing package materials [22,23]. 


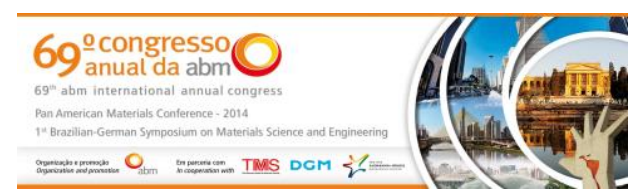

PLA is a hydrolytically degradable aliphatic polyester which presents water vapor permeability that may have a significant influence on its rate of degradation [22]. Is considered a relatively brittle material, thus it needs to be plasticized to produce flexible packaging films by cast film extrusion or blown film extrusion [24,25].

\subsection{Clay and Nanocomposites}

Various inorganic nanoparticles have been recognized as possible additives to enhance the polymer performance such as the layered inorganic solids like nanoclay. Clay nanocomposites with biobased polymer matrices are of increasing scientific and industrial interest have attracted some attention by the packaging industry, due to their low cost, relative simple processability and improvements in some properties of polymers composites. Favorable characteristics include improved Young's modulus, reduced gas permeability, improved fire retardancy, chemical resistance, surface appearance, electrical and thermal conductivity and mechanical properties. In addition, the origin of the polymer matrix from renewable resources is an advantage as well as the biodegradable character of the organic components. Potential applications include melt-processed thermoplastic moulding, packaging films and coatings [22,26-28].

The most studied clay is montmorillonite (MMT), whose chemical general formula is $\mathrm{Mx}\left(\mathrm{Al}_{4}-\mathrm{xMgx}\right) \mathrm{Si}_{8} \mathrm{O}_{20}(\mathrm{OH})_{4}$ [29]. The imbalance of the surface negative charges is compensated by exchangeable cations (typically $\mathrm{Na}^{+}$and $\mathrm{Ca}^{2+}$ ) [30].

This type of clay is characterized by a moderate negative surface charge (cation exchange capacity, CEC), which is an important factor to define the equilibrium layer spacing. The charge of the layer is not locally constant as it varies from layer to layer and must rather be considered as an average value over the whole crystal [31]. MMT clays have hydrophilic nature due to the presence of inorganic cations on the basal montmorillonite layer [32].

MMT clays must be submitted to treatments which play an important role in the preparation of nanocomposites since it can affect their final properties. The most widely used treatments are the diverse functionalizations of clay by various organic cations through ion exchange where the inorganic cations are replaced by organic cations intercalated into the silicate layers. Its hydrophilic nature and ionic exchange capacity allow the silicate mineral to be intercalated by organic cations, which in most cases are alkylammonium ions, to make the clay organophilic and compatible with polymer matrices, preferably with polymers with polar groups which exhibit a higher affinity towards the alkylammonium ion-modified clays [33].

In the immiscible structure the polymer does not penetrate between the clay platelets and the interlayer space of the clay gallery does not expand due to its poor affinity with the polymer, so this structure is also known as phase separated morphology or tactoid morphology. Intercalation is attained when polymer chains slightly penetrate within the gallery space and induce moderate expansion of the clay platelets. Exfoliation is characterized by a random distribution of the clay platelets due to extensive penetration of the polymer chains, resulting in the delamination of the clay platelets and the loss of the crystalline structure of the clay. This is due to a high affinity between polymer and clay [22].

Processing conditions have significant influence on the delamination and dispersion of clay additive in the matrix. The intercalated nanocomposites result from the penetration of polymer into the interlayer region of the clay, resulting in an ordered multilayer structure with alternating polymer/inorganic layers at a repeated distance

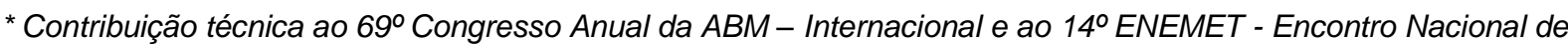
Estudantes de Engenharia Metalúrgica, de Materiais e de Minas, 21 a 25 de julho de 2014, São Paulo, SP, Brasil. 


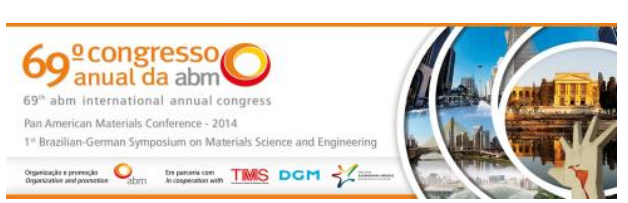

pelletizer, dried again at $60 \pm 2{ }^{\circ} \mathrm{C}$ for $4 \mathrm{~h}$ and fed into extrusion tape to obtain the film samples.

\subsection{Analyses}

$X$-rays diffraction ( $X R D)$ : XRD is most commonly used to probe the nanocomposites structure and occasionally to study the kinetics of the polymer melt intercalation owing to its ease and availability. XRD, in this study was used to evaluate the modification of bentonite light green clay and the intercalation in the PBAT/PLA blend. XRD patterns were recorded on a Simens - D5000 diffractometer operated at $40 \mathrm{kV}$ and $40 \mathrm{~mA}$, with CuK $\alpha$ radiation $(\lambda=15.4 \AA)$.

Cation Exchange Capacity -CEC: CEC of bentonite light green clay determination was carried out by ammonium acetate method [41].

Wavelength Dispersive X-Ray Fluorescence (WDXRF): the main components of bentonite light green clay were determined by using a Rigaku RIX 3000 analyzer.

Melt flow index (MFI) measurements: MFI measurements for PBAT/PLA blend were determined with a microtest extruder plastometer at $190^{\circ} \mathrm{C} / 2.16 \mathrm{~kg}$ conditions (ASTM 1238-04).

Thermogravimetric analysis (TG): were carried out using Mettler-Toledo - TGA/SDTA 851. A sample with $10.0 \pm 1.0 \mathrm{mg}$ of the samples were weighed and then the samples were kept in a platinum sample pan, weighed and heated to $600^{\circ} \mathrm{C}$ starting from room temperature $\left(25^{\circ} \mathrm{C}\right)$, at a heating rate of $10^{\circ} \mathrm{C} / \mathrm{min}$ (in an oxygen atmosphere).

Differential scanning calorimetry (DSC): analyses were carried out using a Mettler Toledo DSC $822 \mathrm{e}$ from 25 to $250^{\circ} \mathrm{C}$ at a heating rate of $10^{\circ} \mathrm{C} / \mathrm{min}$ under oxygen atmosphere. DSC analyses of the materials were performed on four samples of the irradiated and non-irradiated materials.

Mechanical tests: Tensile tests were determined using an INSTRON Testing Machine model 5564, according to ASTM D 882-91 in order to evaluate the mechanical behavior of the materials studied. Each value obtained represented the average of five samples.

Scanning Electron Microscopy (SEM): were carried out using a LX 30 (Philips). The samples were cryofractured under liquid nitrogen, and then the fractured surface was coated with a fine layer of gold and observed by SEM.

\section{RESULTS AND DISCUSSION}

\subsection{Bentonite Light Green Clay Characterization Results}

$X$-rays diffraction $(X R D)$ analysis results: the XRD patterns of natural bentonite light green clay and after be modified by quaternary ammonium salt are showed in Figure 1. The results show that the natural bentonite light green clay presented an interlayer distance (do01) of $1.55 \mathrm{~nm}$ and after modification the interlayer distance increased to (do01) of $2.17 \mathrm{~nm}$. This increase confirms the major intercalation of the quaternary ammonium cation in the interlamellar spacings of the bentonite light green clay took place. These results are also consistent with others clays results [37]. 

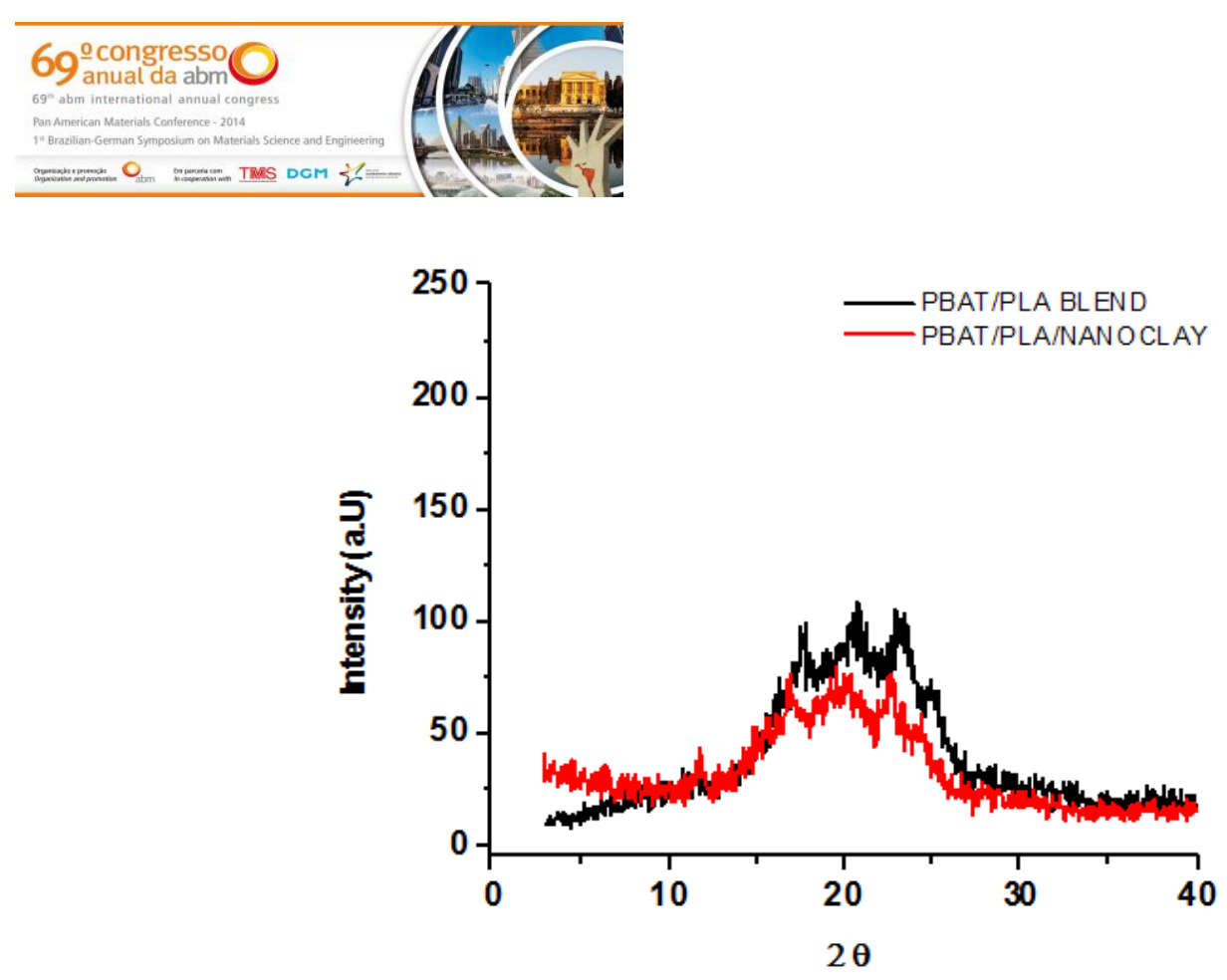

Figure 2. X-rays diffraction patterns of PBAT/PLA Blend and PBAT/PLA/Clay nanocomposite.

It can be seen in Fig. 2, the XRD pattern for PBAT/PLA/Clay nanocomposite show no characteristic organoclay peaks in the range of $2 \theta=4.05^{\circ}$; that is, the peak corresponding to the basal spacing modified bentonite light green clay (do01) of $2.17 \mathrm{~nm}$ has disappeared. This indicates that PBAT/PLA chains have diffused into the gallery of the clay and that the clay has been successfully intercalated in the PBAT/PLA matrix leading to the formation of exfoliated structures.

Thermogravimetric analysis results (TG): The onset temperature of degradation (Tonset), temperature of maximum loss ( $T_{\max }$ ), temperature corresponding to $50 \%$ loss $\left(T_{50} \%\right)$, and overall weight loss have been calculated from the DTG curves $\left(10^{\circ} \mathrm{C} / \mathrm{min}\right)$ and are presented in Table 2.

Table 2. TG analysis results for PBAT, PLA, PBAT/PLA blend and PBAT/PLA/Clay nanocomposite

\begin{tabular}{|c|c|c|c|c|}
\hline Materials & $\begin{array}{l}T_{\text {onset }}^{(a)} \\
\left({ }^{\circ}-C\right)\end{array}$ & 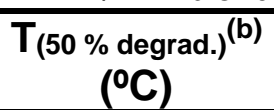 & $\begin{array}{l}T_{\max }(\mathrm{c}) \\
(\mathrm{O} C)\end{array}$ & $\begin{array}{l}\text { Weigh Loss(d) }^{(\mathrm{d})} \\
(\%)\end{array}$ \\
\hline PBAT & 253.2 & 375.4 & 449.1 & 98.82 \\
\hline PLA & 255.4 & 317.2 & 370.2 & 97.22 \\
\hline PBAT/PLA & 307.7 & 380.1 & 447.8 & 98.08 \\
\hline PBAT/PLA/CLAY & 310.2 & 363.6 & 439.5 & 96.64 \\
\hline
\end{tabular}

(a) onset temperature of degradation; (b) temperature of maximum loss; (c) temperature corresponding to $50 \%$ loss; (d) overall weight loss

It was observed in Table 2 an increase of around $50^{\circ} \mathrm{C}$ for PBAT/PLA blend Tonset in comparison with neat PBAT and neat PLA. On the other hand, the clay addition not causes significant changes at PBAT/PLA blend Tonset. The temperature corresponding to $50 \%$ loss $\left(T_{50 \%}\right)$, and $T_{\max }$ were higher for blend than nanocomposite.

Differential Scanning Calorimetry (DSC): Figure 3 shows the curve of DSC analysis of neat PBAT, neat PLA, PBAT/PLA blend and PBAT/PLA/CLAY nanocomposite. 

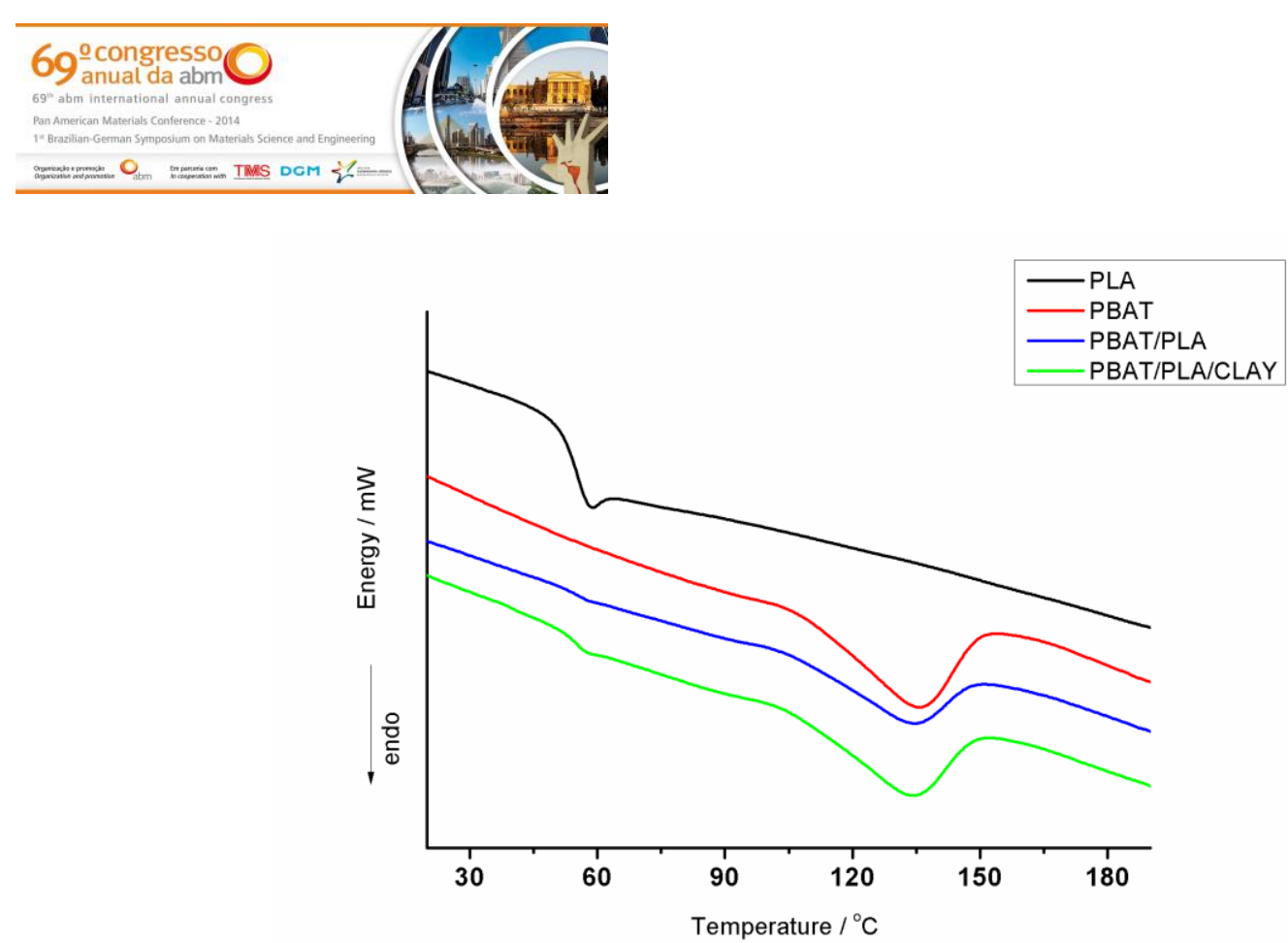

Figure 3. DSC analysis of neat PBAT, neat PLA, PBAT/PLA blend and PBAT/PLA/CLAY nanocomposite.

From figure 3, it could be inferred that compared with the neat PLA the endothermic melting enthalpy of PBAT/PLA blend increased considerably due to blending with PBAT. The addition of clay (3\% in wt) in PBAT/PLA blend leads to obtaining of new material with higher melting enthalpy than original blend. The increases in the melting enthalpy can be attributed to the increase in crystallinity of material. It indicated that blending PBAT with PLA, followed by organophilic Clay addition caused structural changes in the polymeric chains of blend component. It means that blend processing and clay addition had a capability to reorient the polymeric molecules presents in crystal form in order to obtain a composite material with high melting enthalpy and, consequently, high crystallinity percentage.

Table 3. DSC analysis results of materials studied

\begin{tabular}{c|c|c}
\hline Materials & $\begin{array}{c}\text { Melting } \\
\text { Temperature } \\
\left(\mathbf{T}_{\mathbf{m}},{ }^{\circ} \mathbf{C}\right)\end{array}$ & $\begin{array}{c}\text { Melting Enthalpy } \\
\left(\Delta \mathbf{H}_{\mathbf{m}}, \mathbf{J g}^{-1}\right)\end{array}$ \\
\hline Neat PBAT & 135.7 & 298.8 \\
Neat PLA & 58.9 & 43.5 \\
PBAT/PLA blend & 134.4 & 218.8 \\
PBAT/PLA/CLAYnanocomposite & 134.05 & 296.2 \\
\hline
\end{tabular}

The average values of melting enthalpy $(\Delta \mathrm{Hm})$ and melting temperature $(\mathrm{Tm})$ of the materials studied are given in Table 3 . As it can be seen, the melting temperature and enthalpy of blend and composite were higher than of PLA and lower than of PBAT indicating good miscibility between the components of the blend and also suggesting a good incorporation and dispersion of clay nanoparticles in the final composite.

\subsection{Flexible Film Characterization}

Mechanical Tests Results of PBAT/PLA blend and PBAT/PLA/Clay Flexible Film: Table 4 summarizes the mechanical tests results for the flexible film from PBAT/PLA Blend and PBAT/PLA/Clay nanocomposite. These results shown the average values 


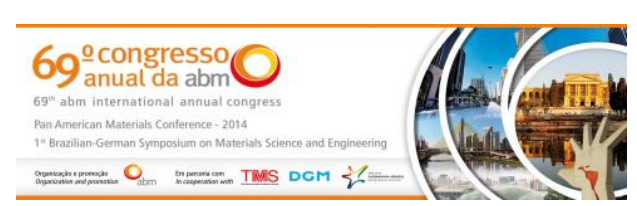

calculated from the data obtained in tests, with standard deviations less than $10 \%$ for all tests.

Table 4. Mechanical tests results for the flexible film from PBAT/PLA Blend and PBAT/PLA/Clay nanocomposite

\begin{tabular}{c|ccc}
\hline Test & $\begin{array}{c}\text { PBAT/PLA } \\
\text { Blend }\end{array}$ & PBAT/PLA/Clay & Variation (\%) \\
\hline $\begin{array}{c}\text { Tensile strength at } \\
\text { break (MPa) } \\
\text { Elongation at break } \\
(\%)\end{array}$ & 10,88 & 14,43 & +30 \\
$\begin{array}{c}\text { Young's Modulus } \\
(\mathrm{MPa})\end{array}$ & 890 & 1051,8 & +18 \\
\hline
\end{tabular}

The results presented in Table 4 shows that the addiction of clay in PLAT/PLA blend improved the tensile strength at break (of around 30\%) and also improved the elongation at break. These changes should be associated with the interfacial interaction between the PBAT and PLA component of blend and Light Green Clay. As it can be seen, the Yong's Modulus has been reduced (of around 28\%).

Figure 4 shows the diagram stress (MPa) $X$ strain (\%) for tensile tests results of Flexible Film from PBAT/PLA blend and from PBAT/PLA/Clay.

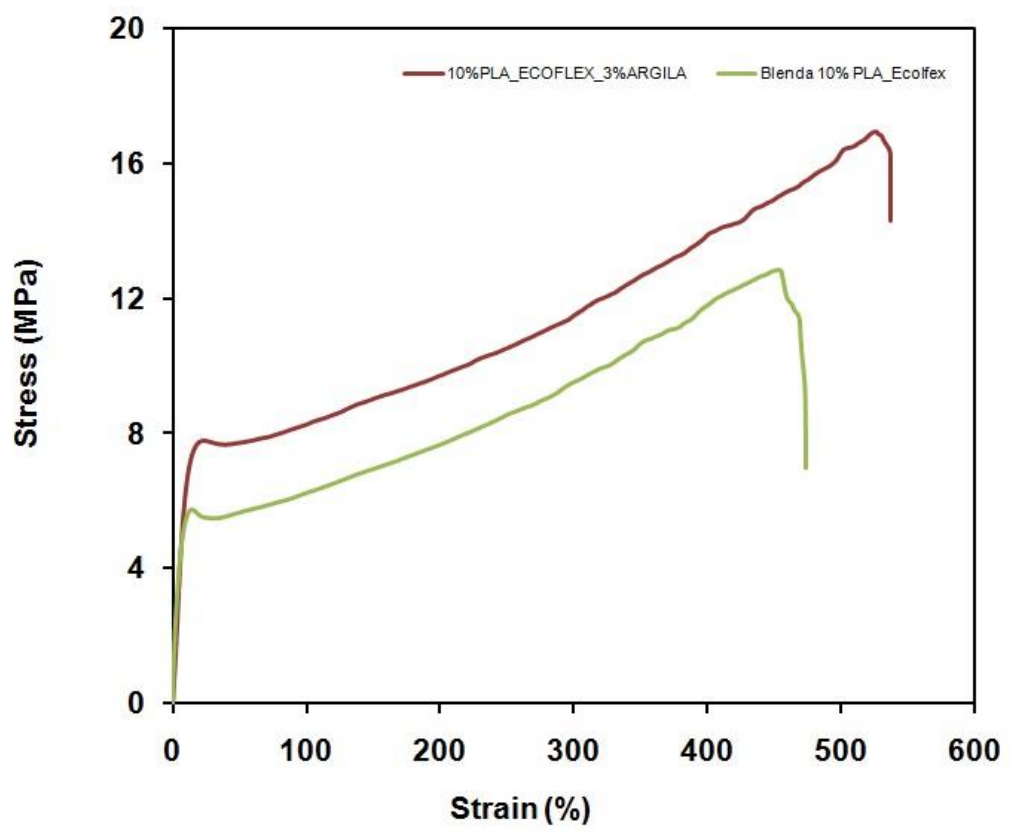

Figure 4. Diagram Stress (MPa) X Strain (\%) for both, PBAT/PLA Blend and PBAT/PLA/Clay

From of stress-strain curve it is possible observed that the addition of modified light green clay makes the PBAT/PLA blend more ductile than original PBAT/PLA blend. This is evident from the elongation at break values of the nanocomposite.

Scanning Electron Microscopy (SEM): SEM micrographs of cryo-fractured surfaces of blend PBAT/PLA and PBAT/PLA/Clay nanocomposite are compared in Figure 5. As it can be seen, PBAT/PLA/Clay nanocomposite, Figure $(5 b)$, showed a slightly rough cryo-fractured surface, when compared with cryo-fractured surface of blend 


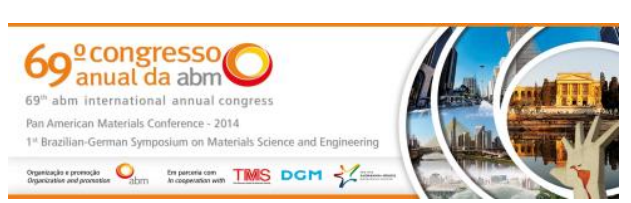

blend improved the thermal degradation temperature increasing the thermal resistance of material as shown in TG results. The peaks of DSC analysis indicated that blending PBAT with PLA, followed by organophilic Clay addition caused structural changes in the polymeric chains of blend component and leads to obtain a composite material with high melting enthalpy and, consequently, high crystallinity percentage. The superior mechanical properties of PBAT/PLA/Clay nanocomposite observed in this study can be attributed to the stiffness of Brazilian bentonite light green clay, reinforcing effects, to the degree of the intercalation and good dispersion of the clay layers in the PBAT/PLA matrix. From the results of XRD and SEM micrographs, is possible claim that the morphology at PBAT/PLA/Clay presents a mixture of intercalated and partially exfoliated structures. This result indicates that PLA and PBAT chains have diffused into the gallery of the clay and the clay has been successfully intercalated in the PBAT/PLA matrix leading to obtain flexible films with improved tensile strength and elongation at break properties when compared with the flexible film prepared from PBAT/PLA blend.

\section{Acknowledgements}

The authors wish to thank BASF and Cromex S.A., for the support for this work.

\section{REFERÊNCIAS}

1 Faruk O, Bledzki AK, Fink HP, Mohini S. Biocomposites reinforced with natural fibers: 2000-2010. Progress in Polymer Science. 2012; Vol. 37: 1552- 1596.

2 Bureau G, Couturier Y, Prudhomme J-C, Coma V. Les biopolymères comme matériaux d'emballage : le principe et les possibilités. Ind. Alim. Agr. 1996, avril, 235-237.

3 Alidedeoglu HA, Kannan G. Evaluation of biodegradable copolyester resins with increase green content. Antec. 2011.

4 Kirvan MJ, Strawbridge JW. Plastics in food packaging. Food Packaging Technology. 2003. 174-240.

5 Avella M, Vlieger JJ, Errico ME, Fischer S, Vacca P, Volpe MG. Biodegradable starch/clay nanocomposite films for food packaging applications. Food Chemistry. 2005;Vol. 93: 467 - 474.

6 Doi Y, Fukuda K. Biodegradable plastics and polymers. Amsterdam: Elsevier. 1994; Eds.: 479-497.

7 Avérous L, Pollet E. Environmental silicate nano-biocomposites.Springer. 2012; Vol. 1: 447p.

8 Huang SJ. Encycl Polym Sci Eng 2: Biodegradable polymers. New York: WileyInterscience; 1985.

9 Yamamoto M, Witt U, Skupin G, Beimborn D, Müller RJ. Biodegradable aliphaticaromatic polyesters: "Ecoflex ${ }^{\circledR}$ ". BASF.

10 Cook WJ, Cameron JA, Bell JP, Huang SJ. Polymer Letters Edition. 1981; Vol. 19: 159165.

11 Nishida H, Okiwa YJ, Environ. Polym. Degrad.1993; Vol. 1: 65

12 Kobayashi T, Hori Y, Kokimoto M, Imai Y. Makromol. Chem. Rapid Commun. 1998; Vol. 14: 785.

13 Jr. Araújo J, Magalhães D, Oliveira NA, Nóbrega MM, Temperini MLA, Matos JR, Wiebeck H. PBAT-PLA Blends Buried In Simulated Soil: Characterization by Differential Scanning Calorimetry, Raman Spectroscopy and Wide Angle X-Ray Diffraction. Journal of Chemical, Biological and Physical Sciences. 2013; Vol. 3: 2858 - 2866.

14 Huang SJ. Biodegradable Polymers. Encyclopedia Polymer Science and Engineering. 1985; Vol. 2. 


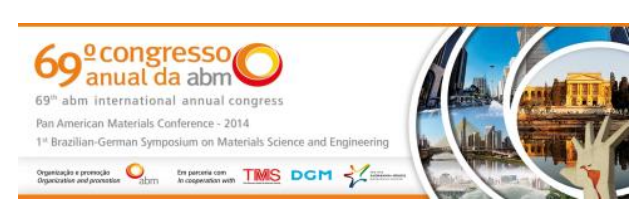

15 Long Y, Dean K,Li L. Polymer blends and composites from renewable resources. Progress in Polymer Science. 2006; Vol. 31: 576 - 602.

16 Sapalidis AA, Katsaros FK, Kanellopoulos NK. PVA/ Montmorillonite Nanocomposites: development and properties. Nanocomposites and Polymers with Analytical Methods. InTech.2011. Acesso em 27/02/2014; 29-50. Disponível em:http://www.intechopen.com/books/nanocompositesandpolymerswithanalyticalmethod s/pvamontmorillonite-nanocomposites-development-and-properties.

17 Schmidt D, Shah D, Giannelis EP. Curr Opin Solid State Mater Science. 2002; Vol. 6: 205-212.

18 Jiang L, Wolcott MP, Zhang J. "Study of biodegradable poly (lactide)/poly (butylene adipate-co-terephthalate) blends". Biomacromolecules. 2005; Vol.7: 199-207.

19 Witt U, Einig T, Yamamoto M, Kleeberg I, Deckwer W-D, Muller R-J. Biodegradation of aliphatic-aromatic copolyesters: evaluation of the final biodegradability and ecotoxicological impact of degradation intermediates. Chemosphere. 2001; Vol. 44(2):289-299.

20 Ozkoc G, Kemaloglu S. Morphology, Biodegradability, Mechanical, and Thermal Properties of Nanocomposite Films Based on PLA and Plasticized PLA. Journal of Applied Polymer Science. 2009; Vol.144:2481-2487.

21 Ljungberg N, Wesslen B. "Tributyl citrate oligomers as plasticizers for poly (lactic acid): thermo-mechanical film properties and aging”. Polymer. 2003; Vol. 44, 7679-7688.

22 Rosa DS, Lenz DM. Biocomposites: Influence of Matrix Nature and Additives on the Properties and Biodegradation Behaviour. Intech. 2013; Chapter 16 : 433-475.

23 Teamsinsungvon A, Ruksakulpiwat Y, Jarukumjorn K. Mechanical and morphological properties of poly (lactic acid)/ poly (butylenes adipate-co-terephtalate)/ calcium carbonate composite. International conference on composite materials. $18^{\text {th }}$ Internacional conference on composite materiails. 2011.

24 Cai, H., V. Dave, R. A. Gross and S. P. McCarthy, 1996, Effects of physical aging, crystallinity, and orientation on the enzymatic degradation of poly (lactic acid), J. Polym. Sci. Part B: Polymer Physics 40, 2701-2708.

25 Pillin I, Montrelay N, Grohens Y. Polymer. 2006; Vol. 47: 4676.

26 Liu A, Berglund LA. Clay nanopaper composites of nacre-like structure based on montmorrilonite and cellulose nanofibers-Improvements due to chitosan addition. Carbohydrate Polymers. 2012; Vol. 87: 53 - 60.

27 Blaker, J J, Lee, K-Y, Bismarck, A. Hierarchical Composites Made Entirely from Renewable Resources Journal of Biobased. Materials and Bioenergy, 5(1): 1-16 (2011).

28 Sorrentino, A, Gorrasi, G, Vittoria, V Potential Perspectives of Bio-Nanocomposites for Food Packaging Applications, Trends in Food Science \& Technology, 18(2): 84-95 (2007).

29 Azeredo HMC, Mattoso LHC, McHugh TH. Nanocomposites in Food Packaging - A Review. Advances in Diverse Industrial Applications of Nanocomposites. 2011; Chapter 4: 57 - 78.

30 Azeredo HMC. Nanocomposites for food packaging applications. Food Research International. 2009; Vol. 42: $1240-1253$.

31 Alexandre M, Dubois P. Polymer-layered silicate nanocomposites: preparation, properties and uses of a new class of materials. Materials Science and Engineering. 2000; Vol. 28: 1 - 63.

32 Arora A, Padua GW. Review: Nanocomposites in Food Packaging. Journal of Food Science. 2010; Vol. 75(1): R43-R49.

33 Kim JT, Lee DY, Oh TS, Lee DH. Characteristics of nitrile-butadiene rubber layered silicate nanocomposites with silane coupling agent. Journal of Applied Polymer Science.2003, Vol. 89(10): 2633-2640.

34 Hegde RR. "Structure and Properties of Nanoclay Reinforced Polymer Films, Fibers and Nonwovens. [doctor thesis]. Tennessee: University of Tennessee; 2009.

35 Weiss, J, Takhistov P. McClements J. Functional materials in food nanotechnology. Journal of Food Science. 2006. Vol. 71; 215 - 223. 
36 Grim ER. Clay mineralogy. 2nd ed. New York: McGraw HillBook Company; 1968.

37 Paiva LB, Morales AR, Valenzuela-Díaz FR. Review article - Organoclays: Properties, preparation and applications. Applied Clay Science. 2008; Vol. 42: 8-24.

38 Delbem MF, Valera TS, Valenzuela-Diaz FR, Demarquette, NR. Modification of Brazilian smectite clay with different quaternary ammonium salts. Química Nova. 2010; Vol. 33(2): 309-315.

39 Wu D, Zhou C, Hong Z, Mao D, Bian Z. "Study on rheological behavior of poly(butylene terephthalate)/montmorillonite nanocomposites". European Polymer Journal. 2005; Vol. 41: 2199-2207.

40 Chang JH, An YU, Kim SJ, Im S. Poly(butylenes terephthalate)/organoclay nanocomposites prepared by in situ interlayer polymerization and its fiber (II). Polymer. 2003; Vol. 44: 5655-5661.

41 Salerno, P. and Mendioroz, S. Preparation of Al-pillared montmorillonite from concentrated dispersions. Applied Clay Science, 22, 2002; Vol. 22, issue 3:115-123. 